\title{
Planejamento e orçamento municipal de Teresina para o crescimento econômico e meio ambiente no período de 2014 a 2016
}

\author{
Teresina's planning and municipal budget for economic growth and \\ environment during 2014 to 2016
}

Sanny Maria dos Milagres Garcia do Nascimento ${ }^{[a]}$, Jaíra Maria Alcobaça Gomes ${ }^{[b, c]}$

\footnotetext{
[a] Universidade Federal do Piauí (UFPI), Programa de Pós-graduação em Desenvolvimento e Meio Ambiente (PRODEMA), Teresina, PI, Brasil

${ }^{[b]}$ Universidade Federal do Piauí (UFPI), Departamento de Economia, Programa de Pós-graduação em Desenvolvimento e Meio Ambiente, Teresina, PI, Brasil

[c] Universidade Federal do Piauí (UFPI), Departamento de Economia, Programa de Pós-graduação em Políticas Públicas, Teresina, PI, Brasil
}

\section{Resumo}

A construção de cidades sustentáveis parte da perspectiva de compatibilidade entre crescimento econômico e prudência ecológica. Nesse âmbito, o presente estudo analisou a incorporação desse paradigma aos instrumentos de planejamento urbano do município de Teresina. Para tanto, selecionaram-se as diretrizes do plano diretor da cidade que atuam diretamente sobre o crescimento econômico e o meio ambiente e examinaram-se a provisão e a execução orçamentária para essas normas, nos exercícios de 2014, 2015 e 2016. Os resultados apontaram para um município que compatibilizou a promoção de atividades produtivas com medidas que diminuíssem as pressões sobre o meio ambiente ao prever no plano diretor critérios relativos à gestão de resíduos sólidos, ao zoneamento ambiental, às áreas verdes, à drenagem urbana, aos rios limpos e ao esgotamento sanitário. Também se percebeu alinhamento entre os instrumentos investigados ao identificar a provisão de recursos para gestão ambiental, saneamento básico, serviços urbanos de limpeza pública e coleta de resíduos, assim como para a promoção de setores produtivos. Mas, ao examinar a execução financeira, verificou-se que menos de 50\% do orçamento previsto para essas áreas foi executado, tendo o município concentrado a execução orçamentária em áreas como Previdência Social, encargos especiais e saúde. Concluiu-se que Teresina incorporou nos instrumentos de planejamento urbano analisados os princípios de cidade sustentável, mas nos exercícios de 2014 a 2016 não priorizou essas áreas com recursos financeiros.

Palavras-chave: Instrumentos de planejamento urbano. Cidades sustentáveis. Crescimento econômico. Meio ambiente.

SMMGN é economista, mestre em Desenvolvimento e Meio Ambiente, e-mail: sannygarcia7@hotmail.com JMAG é professora, e-mail: jaira@ufpi.edu.br 


\section{Abstract}

The construction of sustainable cities starts from the perspective of compatibility between economic growth and ecological caution. In this context, the present study analyzed the incorporation of this paradigm to the Teresina's urban planning instruments. In order to do so, we selected the guidelines of the city master plan that act directly on economic growth and the environment, and examined the provision and budget execution for these standards in 2014, 2015 and 2016. The results revealed a municipality that promoted productive activities with steps that diminish the stress on the environment, by providing a master plan with criteria for solid waste management, environmental zoning, green areas, urban drainage, clean rivers and sanitary sewage. We noticed the alignment between the instruments investigated also identified the provision of resources for environmental management, basic sanitation, urban public cleaning and waste collection services, as well as for the promotion of productive sectors. But in examining the financial execution, we verified that less than $50 \%$ of the budget foreseen for these areas was executed, with the municipality concentrating budget execution in areas such as social security, special expenses and health. We concluded that Teresina incorporated the principles of sustainable city in the urban planning instruments analyzed, but in the years 2014 to 2016 did not prioritize these areas with financial resources.

Keywords: Urban planning tools. Sustainable cities. Economic growth. Environment.

\section{Introdução}

A crescente concentração populacional nas cidades, a expansão da produção e do consumo (bem como o trade off que existe entre crescimento econômico e meio ambiente) revelam o desafio que o planejamento urbano possui em incorporar o estilo de desenvolvimento sustentável.

O planejamento urbano com foco nesse modelo surgiu no contexto internacional no final dos anos 1970 e consolidou-se com a publicação do Relatório Brundtland, em 1987 (Souza, 2006). Já no cenário brasileiro, a inserção da questão ambiental consolidou-se com a promulgação da Constituição Federal de 1988, que também instituiu novas diretrizes para a política urbana ao definir o plano diretor como principal instrumento de planejamento urbano, regulamentando-o por meio da lei complementar 10.257/2001, mais conhecida como "Estatuto da Cidade" (Brasil, 2001).

Nessa concepção, a problemática desse trabalho parte da perspectiva de que os municípios necessitam articular em seus instrumentos de planejamento urbano a compatibilidade entre expansão das atividades produtivas e a prudência ecológica para a construção de cidades sustentáveis.

Teresina, capital do estado do Piauí, foi escolhida como área de estudo devido à sua concentração populacional na área urbana — 94,27\% da população residem em $17 \%$ da área territorial do município (IBGE, 2010; SEMPLAN, 2015) —, pela sua importância econômica para o estado e região Nordeste do país, sendo responsável por $47,7 \%$ do PIB do estado e tendo ocupado, em 2013, a 8o posição no ranking de participação dos 30 maiores municípios do Nordeste (IBGE, 2015), e pelos dez anos que o plano diretor do município completou em 2016.

Assim, essa pesquisa analisa as diretrizes que atuam sobre o crescimento econômico e o meio ambiente do Plano de Desenvolvimento Sustentável Teresina Agenda 2015 averiguando a sua integração com as peças orçamentárias correspondentes aos exercícios de 2014, 2015 e 2016.

Essa investigação estruturou-se a partir das diretrizes do plano diretor que possuem impacto direto sobre a dimensão econômica e ambiental de desenvolvimento. Por conseguinte, estas foram agrupadas em blocos temáticos com vistas à análise de compatibilidade com a perspectiva de desenvolvimento sustentável, examinando sua dotação e execução orçamentária nos exercícios de 2014, 2015 e 2016.

0 trabalho encontra-se organizado da seguinte forma: na parte seguinte fundamenta-se a discussão teórica sobre a relação entre sistema econômico e meio ambiente e sobre os instrumentos de planejamento das cidades; em seguida, revela-se a metodologia empregada na coleta e análise de dados; posteriormente, perscruta-se a integração dos instrumentos de planejamento urbano 
e sua compatibilidade com o estilo de desenvolvimento sustentável; por último, em um exercício de síntese, apontam-se algumas conclusões.

\section{Relação entre sistema econômico e meio ambiente}

0 funcionamento do sistema econômico é focalizado por dois processos básicos: o processo de produção e o de consumo. Diante dessa premissa básica, Cavalcanti (2010) expõe que a visão ortodoxa da economia desconsiderava a existência de qualquer vínculo entre o sistema econômico e o ecológico. Antes tratavam a degradação ambiental como fenômeno externo ao sistema, visto como uma falha de mercado (externalidade) que, por meio de métodos adequados, podia ser corrigida quando internalizada no sistema de preços.

Mueller (2007), ao explicar as relações entre sistema econômico e meio ambiente, rebate a visão ortodoxa da economia, esclarecendo que o sistema econômico está inserido em um meio externo (meio ambiente) com o qual interage. Para produzir bens e serviços, aloca recursos desse meio externo e, em ambos os processos (de produção e consumo) gera resíduos, rejeitos para esse ambiente, causando-lhe degradação.

0 sistema econômico atua em um determinado espaço, alterando-o conforme o seu crescimento. Assim, pode-se dizer que a economia apresenta impactos sobre o meio ambiente, os quais são função da escala (tamanho, dimensão) do sistema econômico e do estilo dominante de crescimento econômico, sendo este o modo pelo qual aquele sistema se expande (Andrade, 2008; Mueller, 2007).

Mueller (2007) acrescenta que a escala da economia global tem dois componentes básicos: a magnitude da população humana e o nível de produção material por habitante. 0 primeiro determinará o comportamento do segundo, ou seja, a dinâmica demográfica indicará a produção de alimentos, o requerimento de espaços geográficos, serviços e, proporcionalmente, as emissões de resíduos, de rejeitos, revelando forte relação com a questão ambiental.

Para Andrade (2008), o tamanho da população e outras variáveis demográficas certamente levam a pressões adicionais sobre a capacidade de os sistemas naturais sustentarem seus processos ecológicos vitais. Aumentos nas populações influenciam o consumo de alimentos, água, energia, abrigo, transporte, elevando a pressão humana sobre o meio ambiente.

Sachs (2002, p. 48) aponta que a humanidade passou a despertar à conscientização ambiental no século XX, com os episódios da bomba atômica (poder de destruição em massa) e da aterrissagem na Lua (finidade de recursos naturais) - episódios reflexivos para a opinião pública quanto às "[...] limitações do capital natureza e dos perigos decorrentes das agressões ao meio ambiente usado como depósito."

A preocupação com o crescimento econômico compatível com a utilização racional de recursos do meio ambiente passou a fazer parte da agenda internacional após a Conferência de Estocolmo, evento que introduziu o despertar da consciência de que o modelo tradicional de expansão das atividades produtivas levaria ao esgotamento completo de recursos naturais, pondo em risco a vida humana (Gadotti, 2002).

Na Conferência de Estocolmo (1972), instituiu-se que a alternativa para o equilíbrio entre essas dimensões não seria um modelo de desenvolvimento com crescimento econômico igual a zero, pois este se faz necessário, mas um paradigma onde esse avanço deveria ser implementado por métodos favoráveis ao meio ambiente, sem favorecer a incorporação predatória do capital (Sachs, 2002).

Em 1987, a Comissão Mundial sobre Meio Ambiente e Desenvolvimento (CMMAD), conhecida como Comissão Brundtland, recomendou a criação de uma nova carta ou declaração universal que apontasse para a incompatibilidade dos padrões de produção e de consumo vigentes, reafirmando a visão defendida nas últimas conferências. Publicado com o título "Nosso Futuro Comum", o documento introduziu um novo modelo para o desenvolvimento das nações, qual seja, o sustentável, definindo-o como "[...] aquele que satisfaz as necessidades presentes, sem comprometer a capacidade das gerações futuras de suprir suas próprias necessidades" (CMMAD, 1991, p. 46).

A discussão sobre esse estilo de desenvolvimento deu-se por intermédio das conferências internacionais (Estocolmo, 1972; CNUMAD, 1992; II Conferência Habitat, 1996; Rio +5, 1997; Rio +10, 2002; Rio+ 20, 2012), levando à conclusão de que um dos pontos de partida para a articulação entre crescimento econômico e meio ambiente está no planejamento das cidades, desencadeando alterações na política urbana no Brasil a partir dos anos 1990. 


\section{Os instrumentos de planejamento urbano brasileiro}

No âmbito jurídico, com a promulgação da Constituição Federal brasileira de 1988, ficaram estabelecidas novas diretrizes para a política urbana nos artigos 182 e 183, que disciplinam e estabelecem técnicas de intervenção no processo de ocupação do espaço das cidades pelo poder público municipal, estipulando como instrumento básico do planejamento urbano o plano diretor municipal (Brasil, 1988).

A CF/1988 também consolida a importância da dimensão ambiental ao atribuir a competência a todos os entes federados de proteger e preservar o meio ambiente (art. 23) e ao apontar o dever do poder público e da coletividade de defender e preservar o meio ambiente ecologicamente equilibrado para as presentes e futuras gerações (art. 225).

No entanto, a regulamentação dessa matéria, em âmbito municipal, veio somente em 2001, com a publicação da lei complementar 10.257, mais conhecida como "Estatuto da Cidade". Além de normatizar a política urbana e os instrumentos de planejamento, o estatuto reforçou a preocupação com o meio ambiente, presente na $\mathrm{CF} / 1988$, e marcou uma nova etapa na política urbana brasileira, ao incorporar o conceito de cidades sustentáveis (Braga, 2011; Ribeiro, 2012; Silva, 2013).

0 estatuto designa, entre as diretrizes para a política urbana, a necessidade de planejamento do desenvolvimento das cidades, da distribuição espacial da população e das atividades econômicas do município, de modo a evitar e a corrigir as distorções do crescimento urbano e seus efeitos negativos sobre o meio ambiente (Brasil, 2001).

Silva (2013) aduz que o estatuto trouxe um novo conceito de urbanização que incorpora valores ambientais aos processos de gestão e ordenamento dos espaços urbanos.

Dada a relação conflituosa entre crescimento econômico e meio ambiente, quanto às pressões causadas sobre este provocadas pela expansão das atividades de produção e consumo e pela necessidade de equilíbrio nessa relação, verifica-se que as diretrizes econômicas e ambientais do plano diretor, instrumento básico do planejamento urbano das cidades brasileiras, precisam estar articuladas, compatíveis com a perspectiva de desenvolvimento proposto pela CMMAD (1991), a fim de que a partir delas os demais instrumentos atuem na implementação de um modelo de produção e consumo que gere menor degradação ambiental.
O EC, no artigo 40, $\S 1$, reconhece o plano diretor como parte integrante do processo de planejamento municipal e estabelece que os instrumentos orçamentários Plano Plurianual (PPA), Lei de Diretrizes Orçamentárias (LDO) e Lei Orçamentária Anual (LOA), já regulamentados como instrumentos de política urbana no art. $4^{\circ}$ da referida lei, estejam em consonância com as diretrizes propostas no plano diretor.

O PPA é um instrumento de planejamento orçamentário que designa diretrizes, objetivos e metas da administração pública para as despesas de capital e outras delas decorrentes e para aquelas relativas aos programas de duração continuada, sendo sua realização vinculada à utilização de recursos orçamentários. Está na estrutura orçamentária como uma peça de médio prazo, pois sua duração é de quatro anos, iniciando sua vigência no segundo ano de mandato e estendendo-se por mais três exercícios (CEPAM, 2005).

A integração do plano diretor com o PPA ocorre quando há conciliação de objetivos entre os dois instrumentos, resultando em provisão de recursos para as diretrizes do plano diretor que necessitam de dotação orçamentária para implementação.

A LDO compõe a estrutura de mecanismos orçamentários da administração pública, indicando as metas e prioridades anuais, sendo uma peça de curto prazo, em virtude de sua vigência ser anual. Atua, ainda, como orientadora na elaboração da LOA e dispõe sobre possíveis alterações orçamentárias na legislação tributária (CEPAM, 2005).

0 resultado fiscal ostentado pelo município ao final de um exercício pode interferir nas metas e, consequentemente, nas prioridades da LDO do ano seguinte, revelando maior ou menor nível de investimento para determinadas áreas.

A LOA é a peça operacional dessa estrutura, sendo responsável por estimar as receitas e fixar as despesas para cada exercício (CEPAM, 2005).

As ações previstas na LOA vinculam-se aos programas setoriais da LDO, seguindo a nomenclatura funcional da despesa estabelecida pelo governo federal, por meio da Portaria no 42, de 14 de abril de 1999, do então Ministério do Orçamento e Gestão, publicada no DOU de 15 de abril de 1999 (Brasil, 2015).

A classificação funcional instituída pela referida portaria é composta de um rol de funções e subfunções prefixadas, as quais servem como agregados dos gastos públicos por área de ação governamental, sendo comum essa estrutura para todas as contas públicas dos três níveis de governo (Brasil, 2015). 
A função de governo é o maior nível de agregação das diversas áreas de atuação do setor público, revelando sua competência institucional, a exemplo da cultura, educação e trabalho, guardando relação com os respectivos ministérios. Já a subfunção representa um nível de agregação inferior à função de governo, evidenciando a natureza da atuação governamental (Brasil, 2015).

As ações orçamentárias previstas anualmente são apresentadas nos Programas de Trabalho da LOA, por meio de projetos, atividades e operações especiais vinculados a subfunções, funções de governo e programas setoriais.

A ação orçamentária do tipo atividade é utilizada como instrumento de programação destinada a alcançar o objetivo do programa setorial a ela vinculado, envolvendo um conjunto de operações que se realizam de modo contínuo e permanente, das quais resulta um produto ou serviço necessário à manutenção da ação pública. Já a ação do tipo projeto atua também como instrumento de programação para atingir o escopo de um programa setorial, porém abrangendo um conjunto de operações limitadas no tempo, das quais expandem a produção pública ou criam infraestrutura para novas atividades ou, ainda, implementam ações inéditas em um prazo determinado (Brasil, 2015). As ações do tipo operações especiais representam despesas que não contribuem para a manutenção, expansão ou aperfeiçoamento de ações de governo.
As ações orçamentárias fixadas na LOA são baseadas nas diretrizes, nos objetivos e nas metas aprovadas no PPA e na LDO, as quais, em conformidade com o EC, devem estar igualmente integradas com o plano diretor.

\section{Metodologia}

Área de estudo

A escolha do plano diretor de Teresina para esse estudo deu-se por fatores como: concentração populacional na área urbana, que representa $17 \%$ da área territorial do município (SEMPLAN, 2015); problemas ambientais, como o fato de estar entre as capitais brasileiras com menor cobertura de coleta de esgoto (SNIS, 2013); e os 10 anos de instituição do quinto plano diretor da cidade - Plano de Desenvolvimento Sustentável de Teresina Agenda 2015.

Teresina é um dos 224 municípios do estado do Piauí. Com área de 1,39 mil km², conta com uma população total de 814 mil habitantes, sendo que $94,27 \%$ destes residem na zona urbana da cidade (IBGE, 2010). 0 município é banhado por dois rios, Parnaíba e Poti, que percorrem, respectivamente, $55,57 \mathrm{~km}$ e 53,73 km de sua superfície, sendo que na zona rural o total é de 58,81 km (SEMPLAN, 2015), como verificado na Figura 1.

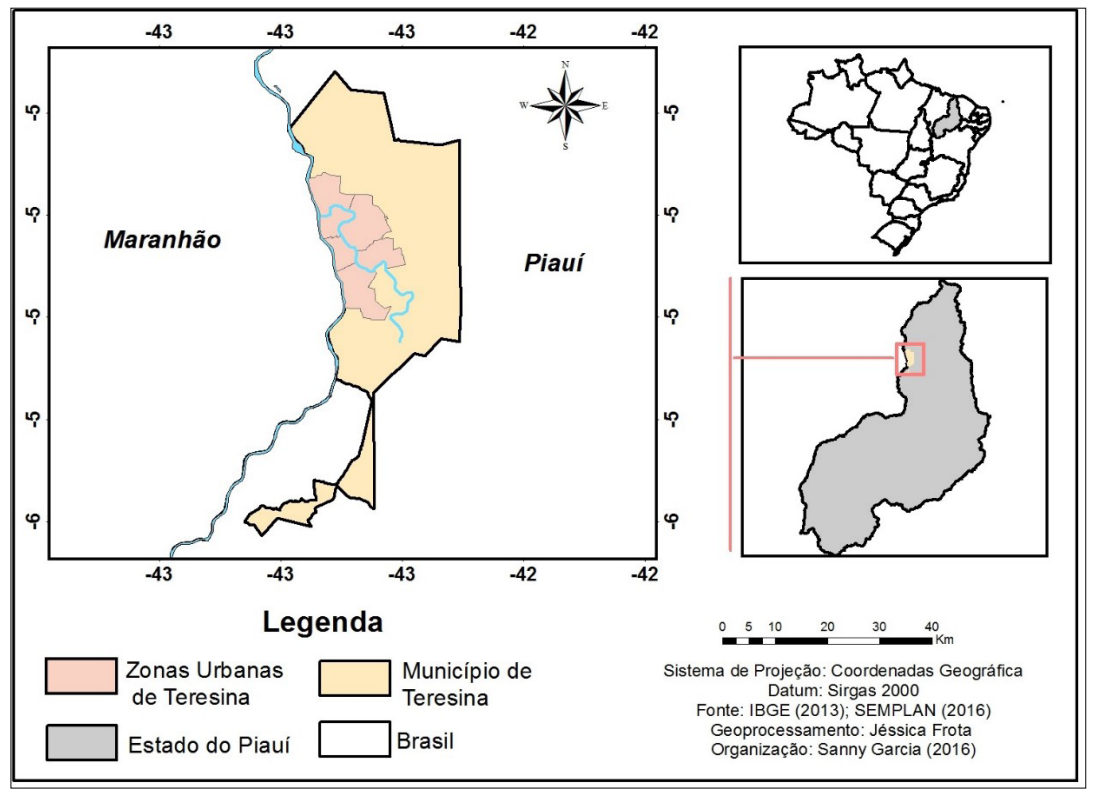

Figura 1 - Localização da área de pesquisa Fonte: SEMPLAN (2015). 
O setor econômico de Teresina com maior representação na composição do produto interno do município é o de serviços, responsável por 70,93\% da produção, seguido dos setores industrial $(28,69 \%)$ e agropecuário (0,38\%) (IBGE, 2016).

Quanto ao saneamento básico, o município atende a $92,8 \%$ da população com água tratada, cobre $17,8 \%$ da área com coleta de esgoto, e trata $14,6 \%$ desse esgoto para reutilização (SNIS, 2013).

\section{Coleta e análise dos dados}

Foram utilizados nessa pesquisa dados de natureza secundária, mediante a execução de pesquisa documental. Os documentos foram coletados nos acervos digitais da Secretaria Municipal de Planejamento e Coordenação (SEMPLAN) e do Portal da Transparência Pública.

Os registros utilizados foram a lei municipal 3.558/2006 (Teresina, 2006), que institui o Plano de Desenvolvimento Sustentável - Teresina Agenda 2015; a Lei Orçamentária Anual (LOA) do período de 2014 a 2016, vinculada ao PPA 2014-2017; e os Relatórios de Despesa por Função e Subfunção do mesmo ínterim.
Assim, selecionaram-se doze diretrizes de Desenvolvimento Econômico (DE) constantes no art. 9 que atuam diretamente sobre a promoção de atividades produtivas, e dezoito de Meio Ambiente (MA) constantes nos art. 13 e art.14 da lei no 3.558/2006 que sofrem pressão direta devido à expansão do sistema econômico.

Tais normas foram agrupadas em doze blocos temáticos a fim de sintetizar a análise de compatibilidade com o estilo de desenvolvimento sustentável, a saber: inovações tecnológicas, promoção econômica, pequenos negócios, arranjos produtivos de moda e turismo, zoneamento ambiental, áreas verdes, rios limpos, redução da poluição do ar, incentivo a empresas, esgotamento sanitário, gestão de resíduos sólidos, drenagem urbana.

A análise do orçamento municipal partiu do exame das dimensões estratégica, por meio da lei 4.483/2013 (Teresina, 2013a), que corresponde ao PPA 2014-2017 do município, e operacional da estrutura orçamentária, feita mediante o exame do programa de trabalho dos seguintes documentos: lei no 4.500/2013, lei no 4.676/2014 e lei no 4858/2015, que correspondem às LOAs para os exercícios de 2014, 2015 e 2016, respectivamente, como mostra a Figura 2.

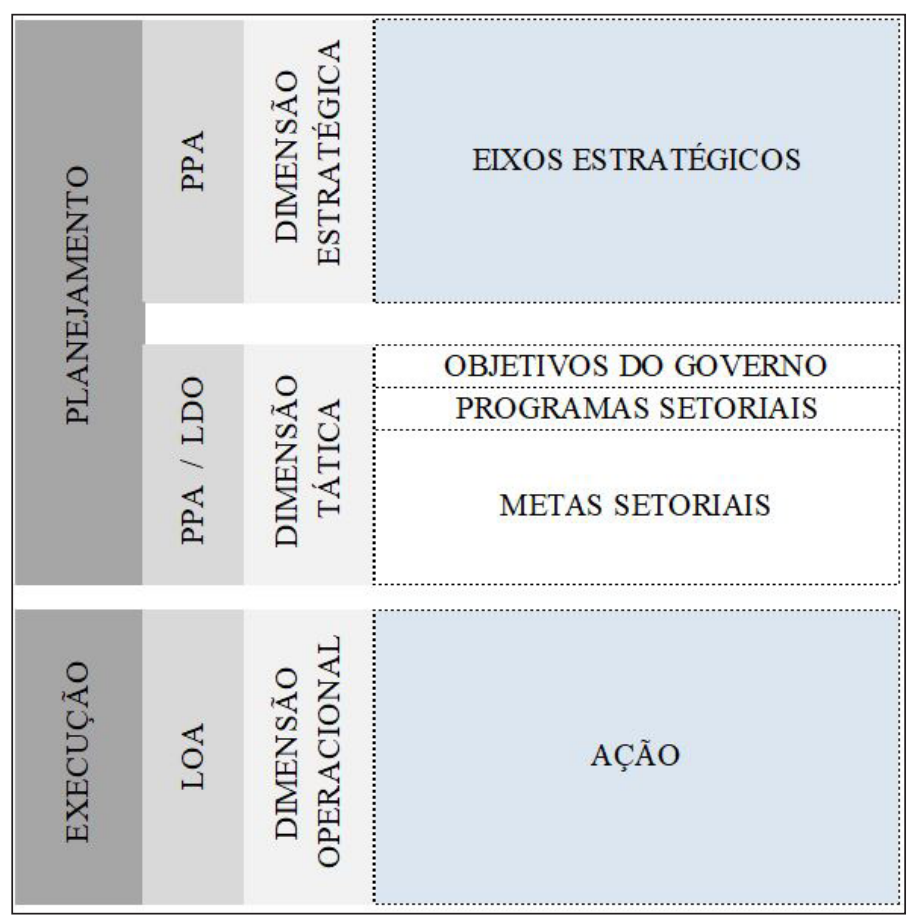

Figura 2 - Estrutura das pecas orcamentárias

Fonte: Adaptaç̃̃o da Figura "Lógica da Gestão" do Anexo I da lei n 4.483/2013 (Teresina, 2013a). 


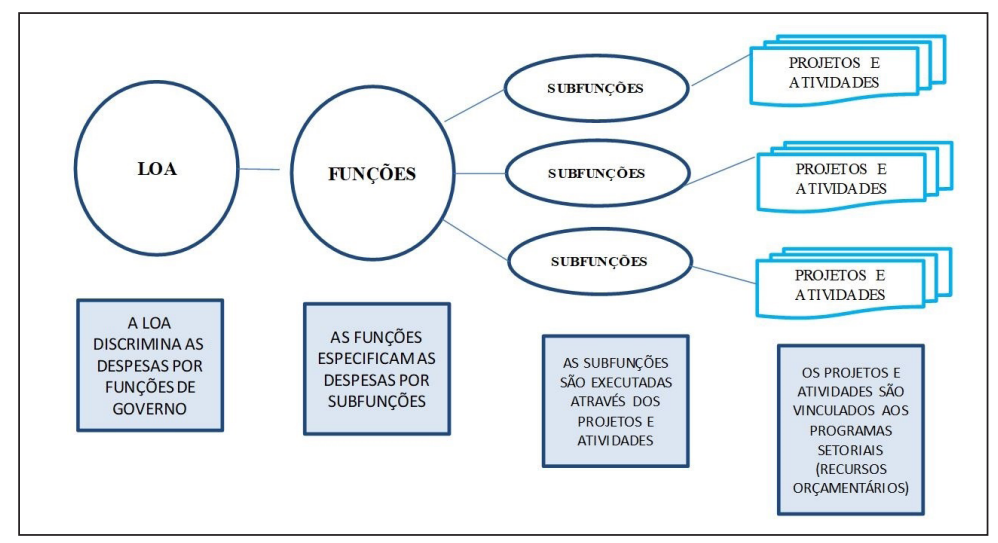

Figura 3 - Estrutura para análise da LOA

Fonte: Elaboracạ̃o própria (2016).

Na proposta orçamentária, identificaram-se as funções de governo que atendiam às diretrizes selecionadas do plano diretor e sua provisão financeira para cada ano. Dada a estrutura da LOA, conforme a Figura 3, as funções estão vinculadas a subfunções e sua execução é realizada por meio de projetos e atividades.

Com base nessa estrutura, das 24 funções de governo tratadas no orçamento (LOA) de Teresina no período analisado, foram identificadas três vinculadas a sete subfunções com dotações orçamentárias para as diretrizes de $\mathrm{DE}$, quais sejam, comércio e serviços, agricultura, indústria, e três funções vinculadas a sete subfunções com dotações orçamentárias para as diretrizes de MA, a saber: urbanismo, saneamento e gestão ambiental.

Para análise da execução financeira do orçamento, utilizaram-se os "Relatórios de Despesa por Função e Subfunção" dos anos de 2014, 2015 e 2016, com vistas a examinar o quanto foi pago do valor orçado para as seis funções identificadas por esse estudo.

Quanto aos dados utilizados do relatório de despesas por função e subfunção, optou-se por trabalhar com o terceiro estágio da execução orçamentária (pagamento), pois, por se tratar do último estágio da despesa da execução orçamentária pública, responde melhor ao objetivo de investigação ora proposta.

\section{Resultados}

\section{As diretrizes do plano diretor de Teresina}

O histórico de planejamento urbano do município aponta para a elaboração de cinco planos diretores entre 1969 e 2006 (Rodrigues, 2013), sendo o último, o Plano de Desenvolvimento Sustentável Teresina Agenda 2015, o primeiro elaborado com base no conteúdo mínimo exigido pelo Estatuto das Cidades ${ }^{1}$.

Todavia, apesar da inclusão da dimensão ambiental nas diretrizes do EC para a política urbana municipal, a não obrigatoriedade de instrumentos que conciliem a expansão de atividades de produção e consumo com o meio ambiente ecologicamente equilibrado deixa a cargo do poder público municipal a responsabilidade de articular essa temática. 0 conteúdo mínimo apresentado pelo EC não garante que políticas que impulsionam a expansão das cidades (o crescimento populacional, por exemplo) ou mesmo as que viabilizam as atividades produtivas estejam articuladas com a conservação do meio ambiente do município.

Ao analisar as 24 diretrizes para o desenvolvimento econômico do plano diretor, contidas no art. 9 da lei 3.558/2006, foram identificadas 12 delas que atuam diretamente sobre a promoção do crescimento econômico do município. Dado o agrupamento em blocos temáticos, verificou-se a predominância de diretrizes que atuam sobre inovações tecnológicas; promoção econômica de atividades de comércio e serviços; pequenos negócios; e arranjos produtivos locais, conforme o Quadro 1.

\footnotetext{
${ }^{1} \mathrm{O}$ conteúdo mínimo apresentado pelo EC para os novos planos diretores estabelecia que deveriam tratar do direito de preempção (art. 25), da outorga onerosa do direito de construir (art. 28 e 29), das operações urbanas consorciadas (art. 32) e da transferência do direito a construir (art. 35), além da delimitação de áreas urbanas para parcelamento, edificação ou utilização compulsória.
} 
Quadro 1 - Diretrizes do plano diretor que ałuam sobre o crescimento econômico

\begin{tabular}{|c|c|c|}
\hline \multicolumn{3}{|c|}{ PLANO DIRETOR } \\
\hline \multicolumn{3}{|c|}{ DIRETRIZES DE DESENVOLVIMENTO ECONÔMICO. ART.9 } \\
\hline BLOCOS TEMÁTICOS & INCISOS & DIRETRIZ \\
\hline 1. INOVAC̣̃̃ES TECNOLÓGICAS & $x$ & $\begin{array}{l}\text { Implementar as iniciativas já elaboradas (agronegócio, informática e artesanato), definin- } \\
\text { do planos de expansão para o Projeto Incubadoras de Empresas. }\end{array}$ \\
\hline \multirow{3}{*}{ 2. PROMOC̣̃̃O ECONÔMICA } & XII & $\begin{array}{l}\text { Fortalecer as políticas de promoç̃o econômica do município, através do fomento às } \\
\text { exportações e incentivos fiscais e locacionais. }\end{array}$ \\
\hline & XIII & $\begin{array}{l}\text { Situar o comércio atacadista e distribuidor e os operadores de transporte rodoviário em } \\
\text { área especifica, dotada da infraestrutura urbanística e dos equipamentos adequados. }\end{array}$ \\
\hline & XIV & Dar continuidade aos esforços para a implantação de uma estação aduaneira de interior. \\
\hline \multirow{3}{*}{ 3. PEQUENOS NEGÓCIOS } & XV & $\begin{array}{l}\text { Avaliar e fortalecer os instrumentos de apoio aos micro e pequenos negócios com assistên- } \\
\text { cia técnica, treinamento e centros de produção. }\end{array}$ \\
\hline & $X V I$ & $\begin{array}{l}\text { Ampliar as alternativas de crédito para micro e pequenos negócios, definindo medidas de } \\
\text { orientação, acompanhamento e avaliação. }\end{array}$ \\
\hline & XVII & Incentivar as exportações, especialmente através de consórcios de pequenas empresas. \\
\hline \multirow{5}{*}{ 4. ARRANJOS PRODUTIVOS LOCAIS } & XVIII & $\begin{array}{l}\text { Promover a ampliação das compras públicas junto ao segmento de micro e pequenas } \\
\text { empresas. }\end{array}$ \\
\hline & XXI & Mobilizar as organizações envolvidas no setor "Confecç,ão e Moda". \\
\hline & XXII & Implantar o comitê gestor do arranio produtivo local "Confecção e Moda". \\
\hline & XXIII & Elaborar o Plano de Desenvolvimento do Turismo de Teresina. \\
\hline & XXIV & Implantar o comitê gestor do arranjo produtivo local Turismo. \\
\hline
\end{tabular}

Fonte: Lei n $n^{0} 3.558$ de 2006 (Teresina, 2006). Elaboração própria (2017).

Averiguou-se que as 12 diretrizes selecionadas formam uma base de incentivo para a expansão do setor privado, atuando em áreas como capacitação, infraestrutura, assistência técnica, crédito, além de incentivos econômicos.

A promoção do crescimento econômico sem instrumentos que atuem sobre as pressões causadas ao meio ambiente é incompatível com o estilo de desenvolvimento proposto pelas conferências internacionais. Por esse motivo, fez-se necessário verificar essa compatibilidade nas diretrizes para o meio ambiente do plano diretor.

Ao analisar as 40 diretrizes contidas no art.13 e as 15 englobadas no art.14 da lei 3.558/2006 para o meio ambiente, constatou-se que 18 atuam sobre as pressões causadas a este. Ao agrupá-las em blocos temáticos, notou-se a predominância de orientações para o zoneamento ambiental, áreas verdes, rios limpos, redução da poluição do ar, esgotamento sanitário, gestão de resíduos sólidos e drenagem urbana, de acordo com o Quadro 2.
As 18 diretrizes foram selecionadas para análise nesse estudo por tratarem de temáticas diretamente afetadas quando não há articulação com o desenvolvimento de processos de produção e consumo. Ao aprofundá-las, concebeu-se que houve preocupação em vinculá-las com os possíveis efeitos que poderiam ser gerados pela expansão de atividades produtivas.

\section{Orçamento municipal de Teresina para o crescimento econômico e meio ambiente}

Uma vez que o Estatuto da Cidade, no artigo 40, $§ 1^{\circ}$, também preconiza que os instrumentos orçamentários devem estar alinhados com o plano diretor, incorporando as diretrizes e prioridades nele contidas, aferiu-se que Teresina também determinou a produtividade econômica e a sustentabilidade ambiental como dois dos cinco eixos do Plano Plurianual 2014-2017.

Nesse sentido, estipulou como objetivos para a dimensão estratégica do orçamento: garantir 
Quadro 2 - Diretrizes do plano diretor que atuam sobre o meio ambiente

\begin{tabular}{|c|c|c|}
\hline \multicolumn{3}{|c|}{ PLANO DIRETOR } \\
\hline \multicolumn{3}{|c|}{ DIRETRIZES PARA 0 MEIO AMBIENTE. ART.13 E ART 14} \\
\hline BLOCOS TEMÁTICOS & INCISOS & DIRETRIZ \\
\hline \multirow{3}{*}{ 5. ZONEAMENTO AMBIENTAL } & $\mathrm{XI}$ & $\begin{array}{l}\text { Cadastrar o patrimônio ambiental do município, mapeando as áreas de reserva florestal, } \\
\text { de preservacão permanente, de parques, pracacs e bosques, as áreas para exploraçã̃o } \\
\text { mineral, de madeira e para uso agropecuário. }\end{array}$ \\
\hline & XII & $\begin{array}{l}\text { Definir classes de aptidão de uso do sítio urbano para as diversas atividades, conservan- } \\
\text { do as áreas de preservação ambiental. }\end{array}$ \\
\hline & XIII & 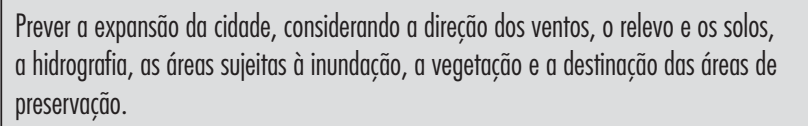 \\
\hline \multirow{2}{*}{ 6. ÁREAS VERDES } & $X V I$ & Criar e implantar novas unidades de conservação nas zonas urbana e rưral. \\
\hline & XVII & Promover a arborização de vias com espécies adequadas \\
\hline \multirow{5}{*}{ 7. RIOS LIMPOS } & XXVIII & Identificar e impedir o lançamento de esgotos nas galerias de águas pluviais. \\
\hline & XXIX & Recuperar a mata ciliar às margens dos rios e riachos, criando parques lineares. \\
\hline & XXX & $\begin{array}{l}\text { Impedir a prática do desmatamento e o uso de agrotóxicos na implantação de lavouras } \\
\text { rurais, às margens dos rios. }\end{array}$ \\
\hline & XXXII & Estabelecer medidas para evitar 0 assoreamento dos rios e riachos. \\
\hline & XXXIII & Monitorar sistematicamente a qualidade das águas. \\
\hline 8. REDUÇÃO DA POLUIC̣ÃO DO AR & XXXIII & Controlar a polviç̦ão atmosférica por veículos e outras fontes. \\
\hline 9. INCENTIVO A EMPRESAS & $\mathrm{XL}$ & $\begin{array}{l}\text { Incentivar, inclusive através de redução ou isenção de tributos municipais, as empresas } \\
\text { dedicadas ao reprocessamento de resíduos. }\end{array}$ \\
\hline 10. ESGOTAMENTO SANITÁRIO & $V^{*}$ & $\begin{array}{l}\text { Fiscalizar, de forma efetiva, a obrigatoriedade das indústrias tratarem seus efluentes de } \\
\text { acordo com as prescriç̄ôes legais. }\end{array}$ \\
\hline \multirow{4}{*}{ 11. GESTÃO DE RESÍDUOS SÓLIDOS } & $1 X^{*}$ & Elaborar plano de gestão para os resíduos sólidos produzidos no município. \\
\hline & $x^{\star}$ & $\begin{array}{l}\text { Montar estruuturas de coleta seletiva, com a construcuão de pontos de triagem de } \\
\text { materiais e implantaçá̃o de programas de associativismo de catadores. }\end{array}$ \\
\hline & $X 1^{\star}$ & Adequar 0 atual aterro de lixo às normas ambientais. \\
\hline & $X I V^{*}$ & $\begin{array}{l}\text { Implementar orientacõoes espećficas para coleta e destinacão de lixo tóxico, contamina- } \\
\text { do ou não, compativel com os meios tradicionais. }\end{array}$ \\
\hline 12. DRENAGEM URBANA & $X V^{*}$ & Elaborar e implantar Plano Diretor de Drenagem Urbana. \\
\hline
\end{tabular}

*Incisos do Art.14 da Lei 3.558 de 2006. Fonte: Lei nº 3.558 de 2006 (Teresina, 2006). Elaboração dos autores (2017).

recursos orçamentários para atrair investimentos; promover a economia solidária e criativa; aprimorar a infraestrutura urbana e rural; ampliar a cobertura verde da cidade; qualificar as políticas de preservação do meio ambiente e de monitoramento do clima e as políticas de saneamento com foco nos resíduos sólidos e na drenagem urbana, nivelando-as com algumas das temáticas estabelecidas no plano diretor.

Dos 12 blocos temáticos que atuam sobre as dimensões econômica e ambiental, elaborados a partir das diretrizes do plano diretor examinado por esse estudo, apenas seis foram atendidos por ações propostas no programa orçamentário do período em tela, a saber: promoção econômica, pequenos negócios, gestão de resíduos sólidos, zoneamento ambiental, áreas verdes e rios limpos.

A análise permitiu a verificação de integração entre os instrumentos de planejamento (plano de diretor e provisão orçamentária) por meio da comparação entre os objetivos das ações (atividades/programas) propostas pela LOA e os propósitos das diretrizes 
para o crescimento econômico e meio ambiente do plano diretor.

Essa comparação identificou seis funções de governo vinculadas a 14 subfunções que preveem dotação orçamentária para ações que são compatíveis com o modelo de desenvolvimento sustentável ao promoverem a expansão de atividades produtivas e conservação ambiental no planejamento urbano, como se vê no Quadro 3.
Contudo, ao analisar o orçamento municipal dos anos 2014 a 2016, notou-se que 70\% da dotação orçamentária foi provisionada para as funções de saúde, urbanismo e educação, restando $30 \%$ para as outras 21 funções, entre as quais, cinco que atuam diretamente sobre a dimensão ambiental e econômica, previstas pelo plano diretor.

Em média, no período analisado, $0,90 \%$ do orçamento foi provisionado para ações (projetos/atividades) na

Quadro 3 - Dotação orçamentária para o crescimento econômico e meio ambiente

\begin{tabular}{|c|c|c|c|}
\hline PLANO DIRETOR & \multicolumn{3}{|c|}{ ORÇAMENTO MUNICIPAL - LOA } \\
\hline Blocos Temáticos & Função de Governo & Subfunção & Atividade/Programa \\
\hline \multirow{7}{*}{$\begin{array}{l}\text { PROMOÇÃO ECONÔMICA E } \\
\text { PEQUENOS NÉGÓCIOS }\end{array}$} & \multirow{3}{*}{ 1. Comércio e Serviços } & 1. Promoção Comercial & Cooperativa Solidária. \\
\hline & & 2. Serviços Financeiros & Modernizar e ampliar o Banco Popular de Teresina. \\
\hline & & 3. Turismo & $\begin{array}{l}\text { Promoção Turística; Instalação de infraestrutura de } \\
\text { equipamentos turísticos; Gestão da microempresa. }\end{array}$ \\
\hline & \multirow{3}{*}{ 2. Agricultura } & $\begin{array}{l}\text { 4. Promoção da Produção } \\
\text { Vegetal }\end{array}$ & Implantação do campo agrícola comunitário. \\
\hline & & $\begin{array}{l}\text { 5. Promoção da Produção } \\
\text { Animal }\end{array}$ & $\begin{array}{l}\text { Apoio à produção animal e implantação e manutenção de } \\
\text { unidades produtoras. }\end{array}$ \\
\hline & & $\begin{array}{l}\text { 6. Promoç̃ão da Produção } \\
\text { Agropecuária }\end{array}$ & $\begin{array}{l}\text { Hortas comunitárias; Campo agrícola; Unidade de } \\
\text { beneficiamento agrícola; Agroindústria; Apoio à assistência } \\
\text { técnica e extensão rural; Ampliaç̃ão/aquisiç̃̃o de insumos } \\
\text { da unidade de compostagem; Implantação e manutenção do } \\
\text { agroturismo; Apoio à bacia leiteira*. }\end{array}$ \\
\hline & 3. Indústria & 7. Promoção da Indústria & Fundo municipal de desenvolvimento econômico (FUMDET). \\
\hline \multirow{4}{*}{$\begin{array}{l}\text { PROMOČ̃O ECONÔMICA E } \\
\text { GESTÃO DE RESÍDUOS SÓLIDOS }\end{array}$} & \multirow{2}{*}{ 4. Urbanismo } & 8. Infraestrutura & $\begin{array}{l}\text { Ampliação e implementação de polos empresarias e coleta } \\
\text { de resíduos sólidos na zona rural }{ }^{*} \text {. }\end{array}$ \\
\hline & & 9. Serviços Urbanos & $\begin{array}{l}\text { Limpeza Pública; Coleta de Resíduos sólidos; Aterro } \\
\text { sanitário; Coleta seletiva*. }\end{array}$ \\
\hline & \multirow{2}{*}{ 5. Saneamento } & $\begin{array}{l}\text { 10. Saneamento Básico } \\
\text { Urbano }\end{array}$ & $\begin{array}{l}\text { Implantação e ampliação de sistema de abastecimento } \\
\text { d'água; Implantação e recuperação da infraestrutura } \\
\text { de abastecimento d'água; Perfuração de poço tubular; } \\
\text { Construção de unidades sanitárias. }\end{array}$ \\
\hline & & 11. Saneamento Básico Rural & $\begin{array}{l}\text { Unidades sanitárias populares; Melhoria e ampliação do } \\
\text { sistema de água; Ampliação do sistema de esgoto; Obras } \\
\text { de macrodrenagem; Construção e ampliação de galerias } \\
\text { pluviais. }\end{array}$ \\
\hline \multirow[t]{2}{*}{$\begin{array}{l}\text { ZONEAMENTO AMBIENTAL E } \\
\text { AREAS VERDES }\end{array}$} & \multirow{3}{*}{ 6. Gestão Ambiental } & 12. Preservação e Conservaç̃̃o & $\begin{array}{l}\text { Avaliação ambiental regional; Criacção de parques municipais; } \\
\text { Promoç̃o da sustentabilidade ambiental; Práticas de } \\
\text { educação ambiental; Monitoramento do clima; Estruturação } \\
\text { e revitalização de parques ambientais. }\end{array}$ \\
\hline & & $\begin{array}{l}\text { 13. Recuperação de áreas } \\
\text { degradadas }\end{array}$ & Implantação de parques. \\
\hline RIOS LIMPOS & & 14. Recursos Hídricos & Monitoramento dos recursos hídricos. \\
\hline
\end{tabular}

*Subfunções onde há mais projetos/atividades relacionadas no programa de trabalho, mas que foram suprimidos devido à extensão de conteúdo e não compatibilidade com o objeto de estudo da pesquisa. Fonte: Elaboração dos autores (2017). 
área de gestão ambiental; 3,81\% para saneamento básico; e 1,49\% e 0,69\% para ações que atuam sobre a promoção de atividades como Comércio e Serviços e Agricultura, respectivamente, conforme disposto na Tabela 1.

Segundo o plano de trabalho da LOA, as funções saúde e educação previam atividades/projetos que deveriam atuar na atenção básica; assistência hospitalar e ambulatorial; vigilância sanitária e epidemiológica; ensino fundamental, médio e profissional do município.
Entretanto, o aporte de recursos previstos no programa de trabalho do orçamento municipal não garante a execução financeira dos recursos durante os exercícios analisados.

Ao examinar o relatório de despesas por funções e subfunções de cada ano, quanto à execução financeira (pagamento) de recursos orçados, concebeu-se que as funções que tiveram maior execução não foram, necessariamente, as que tiveram maior provisão orçamentária, conforme pode ser visto na Tabela 2.

Tabela 1 - Dotação Orçamentária de Teresina, por funções de governo, de 2014 a 2016

\begin{tabular}{|c|c|c|c|c|c|}
\hline Ranking* & $\begin{array}{l}\text { Funções de } \\
\text { Governo }\end{array}$ & $2014(\%)$ & $2015(\%)$ & $2016(\%)$ & $\begin{array}{l}\text { Média de participação sob } \\
\text { o orçamento do período } \\
\text { (\%) }\end{array}$ \\
\hline $1^{\circ}$ & Saúde & 32,12 & 30,06 & 30,30 & 30,83 \\
\hline $2^{0}$ & Urbanismo & 18,93 & 20,78 & 21,07 & 20,26 \\
\hline $3^{0}$ & Educação & 19,34 & 20,23 & 18,41 & 19,32 \\
\hline $9^{0}$ & Saneamento & 1,58 & 1,20 & 1,03 & 1,27 \\
\hline $11^{\circ}$ & Gestão Ambiental & 1,08 & 1,01 & 0,62 & 0,90 \\
\hline $16^{\circ}$ & Comércio e Servictos & 0,51 & 0,56 & 0,42 & 0,50 \\
\hline $18^{\circ}$ & Agricultura & 0,19 & 0,27 & 0,23 & 0,23 \\
\hline \multirow[t]{2}{*}{$23^{\circ}$} & Indústria & - & 0,01 & 0,00 & 0,00 \\
\hline & TOTAL DO ORCAMENTO & $R \$ 2.498 .851 .424,00$ & $\mathrm{R} \$ 2.816 .711 .509,00$ & $\mathrm{R} \$ 2.993 .294 .001,00$ & $100,00 \%$ \\
\hline
\end{tabular}

*Para 0 período analisado, foram identificadas 24 áreas de atuação (funções de governo), sendo suprimidas por não estarem dentro do objetivo estudo. Fonte: Lei Municipal 4.500/2013 (Teresina, 2013b); Lei Municipal 4.676/2014 (Teresina, 2014); Lei Municipal 4.858/2015 (Teresina, 2015).

Tabela 2 - Execução financeira de Teresina, por funç̃ões de governo, de 2014 a 2016

\begin{tabular}{|c|c|c|c|c|c|}
\hline Ranking* & Funções de Governo & $2014(\%)$ & $2015(\%)$ & $2016(\%)$ & $\begin{array}{c}\text { Média execução do } \\
\text { orçamento previsto } \\
(\%)\end{array}$ \\
\hline $1^{0}$ & Previdência Social & 104,56 & 118,78 & 113,73 & 112,36 \\
\hline $2^{0}$ & Encargos Especiais & 79,54 & - & 135,29 & 107,41 \\
\hline $3^{0}$ & Saúde & 105,01 & 104,18 & 107,16 & 105,45 \\
\hline $10^{\circ}$ & Urbanismo & 43,71 & 42,66 & 45,53 & 43,97 \\
\hline $15^{\circ}$ & Gestão Ambiental & 26,18 & 4,32 & 32,68 & 21,06 \\
\hline $17^{\circ}$ & Comércio e Serviços & 28,54 & 18,42 & 0,56 & 15,84 \\
\hline $18^{\circ}$ & Agricultura & 29,13 & 7,45 & 7,50 & 14,70 \\
\hline $19^{\circ}$ & Saneamento & 31,71 & 4,14 & 2,89 & 12,91 \\
\hline \multirow[t]{2}{*}{$24^{\circ}$} & Indústria & - & 0 & 0 & 0,00 \\
\hline & TOTAL DA DESPESA & $\operatorname{R} \$ 2.072 .856 .391,71$ & $\mathrm{R} \$ 2.264 .914 .424,55$ & $\operatorname{R} \$ 2.533 .265 .906,51$ & \\
\hline
\end{tabular}

*Para o período analisado, foram identificadas 24 áreas de atuação (funç̃os de governo), sendo suprimidas por não estarem dentro do objetivo do estudo. Fonte: Relatório de despesa por funç̃õo e subfunção dos exercícios de 2014, 2015 e 2016. 
Quanto às funções de governo que tratam de previdência social e encargos sociais, que ocupavam, respectivamente, o 5ㅇ e 8o lugares no ranking de orçamento, quando calculada a média de participação sobre o orçamento anual, tiveram execução financeira acima do que foi provisionado. Por sua vez, as funções de governo que atendem às temáticas propostas pelo plano diretor para as dimensões econômica e ambiental do município tiveram execução financeira abaixo do previsto no orçamento.

Das funções alinhadas aos blocos temáticos do plano diretor, a função urbanismo, que trata da temática de gestão de resíduos sólidos, foi a que garantiu melhor desempenho perante as demais propostas, executando, em média, $43,97 \%$ do orçamento previsto para essa função.

\section{Considerações finais}

Os resultados patentearam que o Plano de Desenvolvimento Sustentável Teresina Agenda 2015 articulou diretrizes que impulsionaram o crescimento econômico ao mesmo tempo em que atuaram na conservação do meio ambiente da cidade ao tratarem, em seu instrumento básico de planejamento, de metas que atuam sobre inovações tecnológicas, promoção econômica, arranjos produtivos locais articulados com normas para o zoneamento ambiental, manutenção de áreas verdes, limpeza dos rios, redução da poluição do ar, bem como outras medidas que possibilitam orientar os demais instrumentos do planejamento urbano da cidade no sentido de executar um desenvolvimento com crescimento econômico e prudência ecológica.

Não obstante, na análise da dimensão operacional do orçamento, nos exercícios de 2014 a 2016, para as temáticas compatíveis com o modelo de desenvolvimento sustentável, apreendeu-se que a dotação orçamentária, necessariamente, não resultou em execução financeira.

Ademais, no orçamento municipal do período de 2014 a 2016, foram previstos recursos para seis das doze temáticas propostas pelo plano diretor. Quanto à execução financeira, apenas duas — promoção econômica e gestão de resíduos sólidos - tiveram execução orçamentaria significativa, ambas vinculadas à função urbanismo, que previu recursos para ações como ampliação e implementação de polos empresariais no município, limpeza pública, coleta de resíduos sólidos (urbano e rural), coleta seletiva e aterro sanitário.

Por conseguinte, depreendeu-se que o município de Teresina tem instrumentos de planejamento urbano capazes de promover a construção de um desenvolvimento com crescimento econômico e prudência ecológica. Apesar disso, durante o período analisado, não priorizou as funções de governo que atuam nessas áreas, executando recursos para setores que sofrem maior pressão da sociedade, a exemplo da saúde, educação e serviços públicos básicos.

\section{Referências}

Andrade, D. C. (2008). Economia e meio ambiente: aspectos teóricos e metodológicos nas visões neoclássica e da economia ecológica. Leituras de Economia Política, 14, 1-31. Recuperado em 8 de agosto de 2015, de http:// www.revistalep.com.br/index.php/lep/index

Braga, R. (2011). Gestão ambiental no Estatuto da Cidade: alguns comentários. In P. F. Carvalho, \& R. Braga (Eds.), Perspectivas de gestão ambiental em cidades médias (pp. 111-119). Rio Claro: LPMUNESP.

Brasil. (1988, 5 de outubro). Constituição da República Federativa do Brasil, de 5 de outubro de 1988. Brasília: Diário Oficial da União. Recuperado em 8 de agosto de 2015, de http://www.planalto.gov.br/ccivil_03/constituicao/ constituicao.htm

Brasil. (2001, 11 de julho). Lei no 10.257, de 10 de julho de 2001. Regulamenta os Art.182 e 183 da Constituição federal estabelece diretrizes gerais da política urbana e dá outras providências. Brasília: Diário Oficial da União. Recuperado em 8 de agosto de 2015, de http://www.planalto.gov.br/ Ccivil_03/leis/LEIS_2001/L10257.htm

Brasil. Ministério do Planejamento Orçamento e Gestão. (2015). Manual Técnico de Orçamento (MTO). Brasília: MP.

Cavalcanti, C. (2010). Concepções da economia ecológica: suas relações com a economia dominante e a economia ambiental. Estudos Avançados, 24(68), 53-67. http://dx.doi. org/10.1590/S0103-40142010000100007

Comissão Mundial sobre Meio Ambiente e Desenvolvimento - CMMAD. (1991). Nosso futuro comum. Rio de Janeiro: Editora da Fundação Getúlio Vargas.

Fundação Prefeito Faria Lima - CEPAM. (2005). Plano diretor passo a passo. São Paulo: CEPAM. 
Gadotti, M. (2002). Agenda 21 Global e a Carta da Terra. In R. H. Born (Ed.), Diálogos entre as esferas global e local: contribuições de organizações não-governamentais e movimentos sociais brasileiros para a sustentabilidade, equidade e democracia planetária (pp. 49-66). São Paulo: Petrópolis.

Instituto Brasileiro de Geografia e Estatística - IBGE. (2010). Censo demográfico. Rio de Janeiro: IBGE.

Instituto Brasileiro de Geografia e Estatística - IBGE. (2015). Produto Interno Bruto dos municípios 2010-2013. Rio de Janeiro: IBGE.

Instituto Brasileiro de Geografia e Estatística - IBGE. (2016). Produto Interno Bruto dos municípios 2014. Rio de Janeiro: IBGE.

Mueller, C. C. (2007). Os economistas e as relações entre o sistema econômico e o meio ambiente. Brasília: Editora Universidade de Brasília, Finatec.

Ribeiro, L. C. Q. A. (2012). 0 Estatuto da Cidade e a questão urbana brasileira. In L. C. Q. A. Ribeiro, \& A. L. Cardoso (Eds.). Reforma urbana e gestão democrática: promessas e desafios do Estatuto da Cidade (2. ed., pp. 11-25). Rio de Janeiro: Revan.

Rodrigues, R. S. (2013). A evolução dos planos urbanos de Teresina no contexto do planejamento urbano no Brasil. In Anais do III Seminário Regional Norte e Nordeste de Pósgraduação em Geografia. João Pessoa: UFPB. Recuperado em 8 de agosto de 2015, de http://www.gerur-ufpi. com/\#!artigos/q2twi

Sachs, I. (2002). Caminhos para o desenvolvimento sustentável. Rio de Janeiro: Garamound.

Secretaria Municipal de Planejamento - SEMPLAN. (2015). Teresina: caracterização do município. Teresina: PMT.

Silva, C. S. G. (2013). Política urbana brasileira: em busca de cidades sustentáveis. Revista Jus Navigandi, 18, 1-2.
Recuperado em 8 de agosto de 2015, de https://jus.com. br/artigos/23856

Sistema Nacional de Informações sobre Saneamento - SNIS. (2013). Diagnóstico dos serviços de água e esgotos 2013. Brasília: Secretaria Nacional do Saneamento Ambiental.

Souza, M. (2006). Desenvolvimento urbano sustentável e planejamento ecológico: avanço, resistência e retrocesso (Parte II). In M. Souza, Mudar a cidade: uma introdução crítica ao planejamento (4. ed., pp. 145-148). Rio de Janeiro: Bertrand Brasil.

Teresina. (2006, 27 de outubro). Lei no 3.558, de 20 de outubro de 2006. Restitui o Plano Diretor de Teresina, denominado Plano de Desenvolvimento Sustentável - Teresina Agenda 2015, e dá outras providências. Teresina: Diário Oficial do Município.

Teresina. (2013a, 27 de dezembro). Lei no 4.483 de 25 de dezembro de 2013. Dispõe sobre o Plano Plurianual para o quadriênio de 2014/2017. Teresina: Diário Oficial do Município.

Teresina. (2013b, 27 de dezembro). Lei no 4.500 de 20 de dezembro 2013. Estima a receita e fixa a despesa do município de Teresina para o exercício financeiro de 2014. Teresina: Diário Oficial do Município.

Teresina. (2014, 31 de dezembro). Lei no 4.676 de 29 de dezembro de 2014. Estima a receita e fixa a despesa do município de Teresina para o exercício financeiro de 2015. Teresina: Diário Oficial do Município.

Teresina. (2015, 31 de dezembro). Lei no 4.858 de 29 de dezembro de 2015. Estima a receita e fixa a despesa do município de Teresina para o exercício financeiro de 2016. Teresina: Diário Oficial do Município.

Recebido: Maio 04, 2017

Aprovado: Fev. 14, 2018 